DOI: 10.20472/IAC.2019.052.025

KYLO-PATRICK HART

Texas Christian University, United States

\title{
SOCIALLY CONSTRUCTING A MORAL UTOPIA: REPRESENTING RURAL SPACES AND PLACES IN AMERICAN MOVIES ABOUT HIV/AIDS
}

\begin{abstract}
:
With regard to American movies about HIV/AIDS, the social construction of rural spaces and places is one that is much more innocent and pure than the social construction of urban environs. Accordingly, this presentation analyzes the social construction of rural locations as a moral utopia in representative AIDS movies made and released in the United States during the first two decades of the AIDS pandemic. It articulates the representational connections in such offerings between traditional ways of being and purity, values of the past and wholesome continuity, innocent iconography and patriarchal expectations. When all is said and done, this presentation demonstrates how rural spaces and places in American AIDS movies came to represent all that is morally good and pure in U.S. society, in dramatic contrast to representations of urban spaces and places and their continual associations with excess, depravity, monstrosity, pollution, and sickness. It further demonstrates how these influential representations regularly reinforced inaccurate perceptions of HIV/AIDS as a threat almost exclusively to residents of urban environments, thereby concealing more accurate social information about the realities of the AIDS pandemic and the range of individuals in all sorts of spaces and places - who needed to proactively protect themselves from its spread.
\end{abstract}

\section{Keywords:}

cinema, HIV/AIDS, media, purity, representation, rural areas, social constructionism, utopia

JEL Classification: 110, L82, N90 